\title{
Assessment standards, Van Hiele levels, and grade seven learners' understandings of geometry
}

\author{
Nosisi Feza and Paul Webb \\ Department of Science, Mathematics and Technology Education, University of Port Elizabeth \\ Email: nosisi.feza@nmmu.ac.za and paul.webb@nmmu.ac.za
}

\begin{abstract}
A number of researchers in mathematical education assert that the instruction in geometry offered in South African schools is inadequate and that traditional teaching strategies do little to promote teachers understandings of their learners' levels of mathematical thought. Van Hiele specifically states that the inability of many teachers to match instruction with their learners' levels of geometrical understanding is a contributing factor to their failure to promote meaningful understandings in this topic. This study investigated whether a sample of grade seven learners in previously disadvantaged primary schools met both the assessment criteria for geometry as stated by the South African Revised National Curriculum Statement and the implied Van Hiele thinking levels. The data generated suggest that none of the 30 learners who participated in this study had attained these requirements and that language competency in general is a barrier to the attainment of higher levels of understanding amongst this group of secondlanguage learners. It is suggested that not only Van Hiele Levels and Assessment Standards, but also learners' cultural background and their specific use of words in the vernacular context, need to be taken into consideration by teachers when developing learning programmes. Possible strategies to meet these requirements are suggested.
\end{abstract}

\section{Introduction}

Internationally there appears to be widespread realisation that teaching in mathematics in general has failed to overcome a number of cognitive barriers to learner understanding (Carpenter \& Fennema, 1988; Kempa, 1993; Peterson, 1998). Likewise, a number of researchers in mathematical education assert that the instruction in geometry offered in South African schools is inadequate in terms of providing learners with the necessary skills needed to operate at the level of axiomatic thinking required for most high school courses (McAuliffe, 1999). Mansfield and Happs (1996) note that traditional teaching strategies do little to promote teachers understandings of their learners' levels of mathematical thought and Van Hiele (1986) specifically states that the inability of many teachers to match instruction with their learners' levels of geometrical understanding is a contributing factor to their failure to promote meaningful understandings in this topic.

A comparison of the assessment standards of the South African mathematics curriculum with Van Hiele descriptors suggests that in terms of geometry South African learners who have completed primary school should have reached Van Hiele's thinking level two, i.e., they should be "able to describe and represent the characteristics and relationships between 2-D shapes and 3-D objects in a variety of orientations" (Department of
Education, 2002: 6). This study investigates whether a sample of grade seven learners who had recently completed their intermediate phase of schooling in previously disadvantaged primary schools meet both the assessment criteria for geometry as stated by the Intermediate Phase Revised National Curriculum Statement (Department of Education, 2002) and the requirements of Van Hiele thinking at level two. This has been done in order to get an indication of the probable (but not generalisable) level of learners' understanding in geometry at the end of their primary schooling and, as such, to raise teachers' awareness of what may be reasonably expected of children who have come through previously disadvantaged South African primary schools.

\section{Background and significance}

It has become apparent since the release of the De Lange Report in 1981 that the problems surrounding science and mathematics education contribute significantly to the current South African national crisis in education. After the installation of the Nationalist government (and consequent adoption of apartheid as a national policy) in South Africa in 1948, a system of 'Bantu Education' was introduced for black South Africans (Samuel, 1990). Bantu Education was for black people and was to be largely based in the 
Bantustans or homelands where 'natives' would be prepared for a life in reserves (Davies, 1986), with different and inferior curricula - usually with no science or mathematics offerings (Hartshorne, 1992). The impact of that system can be seen even today and the children participating in this study all had teachers who are products of Bantu Education. These teachers were under-qualified to teach mathematics and were teaching in under-resourced schools, mainly in rural areas of the Eastern Cape. This study should make a contribution to our understanding of these children's understanding of geometry after a period of learning in this context and, hopefully, provide some indicators of what is needed in order to successfully teach geometry to children in similar schools and social conditions.

\section{Van Hiele and the development of geometrical thinking}

Van Hiele (1986) hypothesised five sequential levels of geometric reasoning. They are labelled visualisation, analysis, informal deduction, formal deduction, and rigour, which describe the characteristics of the thinking process (Burger \& Shaughnessy, 1986). The model suggests that, assisted by appropriate instructional experiences, the learner moves sequentially from the initial or basic level (visualisation), where space is simply observed and the properties of figures are not explicitly recognised, through the sequence listed above to the highest level (rigour), which is concerned with formal abstract aspects of deduction (Fuys \& Liebov, 1997). At level one of the Van Hiele hierarchies the analysis of geometric concepts begins (visualisation is at level zero). For example, through observation and experimentation learners begin to discern the characteristics of figures. These emerging properties are then used to conceptualise classes of shapes. Learners at this level cannot yet explain relationships between properties, interrelationships between figures are still not seen, and definitions are not yet understood.

At the level of informal deduction (level two) learners are able to establish the interrelationship of properties both within figures (e.g., in a quadrilateral, opposite sides being parallel necessitates opposite angles being equal) and among figures (a square is a rectangle because it has all the properties of a rectangle). Thus they can deduce properties of a figure and recognise classes of figures. Class inclusion is understood and definitions are meaningful. Informal arguments can be followed and given but the learner at this level does not comprehend the significance of deduction as a whole or of the role of axioms. Empirically obtained results are often used in conjunction with deduction techniques. Formal proofs can be followed, but learners do not see how the logical order could be altered nor do they see how to construct a proof starting from different or unfamiliar premises.

At level three learners understand the significance of formal deduction as a way of establishing geometric theory within an axiomatic system. They are able to see the interrelationship and role of undefined terms, axioms, postulates, definitions, theorems, and proof. Learners at this level can construct, not just memorise, proofs; they accept the possibility of developing a proof in more than one way. The interaction of necessary and sufficient conditions is understood; distinctions between a statement and its converse can be made.

Level four (rigour) is the highest Van Hiele level. At this level learners can work in a variety of axiomatic systems, that is, non-Euclidean geometries can be studied, and different systems can be compared. Geometry is seen in the abstract.

What is important in terms of pedagogy is that, as Wirszup (1976) suggests, people at different levels of mathematical understanding speak, use and understand terms differently, and that teachers often use terms that can only be understood by learners who have progressed to the third or fourth Van Hiele level. Consequently, when trying to communicate with learners who operate at lower levels, their intentions may be completely misunderstood. A major purpose for distinguishing learners' levels of understanding is to recognise obstacles that they may experience in the learning process, and to allow teachers to develop strategies which will enable children to progress in terms of conceptual development (Bishop, 1997). Austin and Howson (1979) confirm that there is a major difference in mental preparation for mathematics learning between a learner whose language makes use, in some recognisable form, of international Greek-Roman terminology, and its prefixes (pre-, post-, anti-, sub-, co-, mono-, etc.), suffixes (-ation, -or, -ant, -ise, etc.) and roots (equ, arithm, etc.), and a learner whose language contains neither these items nor translation equivalents of them.

\section{Van Hiele levels and the Revised National Curriculum Statement}

The intermediate phase assessment standards for geometry as expressed in the South African Revised National Curriculum Statement (RNCS) documents require that learners are able to name 
shapes, describe and/or classify shapes using properties, and construct shapes correctly in order to attain learning outcome three, i.e., that:

The learner is able to describe and represent the characteristics and relationships between 2-D shapes and 3D objects in a variety of orientations and positions. (Department of Education, 2002: 6)

At Van Hiele level zero (Fuys \& Liebov, 1997) the learner identifies, names, compares and operates on geometric figures according to their appearance. Similarly the RNCS (Department of Education, 2002) assessment standards, which are guided by Van Heile levels, are characterised by the naming and visualising of shapes and objects in natural and cultural forms. As such, both Van Hiele and the RNCS assessment standards characterise this level by recognition of the shape as a whole.

Van Hiele level one is characterised by the analysis of figures in terms of their components and their relationships, a stage which allows learners to discover properties/rules of a class of shapes empirically. The characteristics of the RNCS's assessment standards are the definition of shapes and objects in terms of properties such as their faces, vertices and edges. The characteristics of both the Van Hiele level and the assessment standards are concurrent in that they define shapes and objects using their properties.

At the informal deduction level (Van Hiele level two) learners logically relate previously discovered properties/rules by giving or following informal arguments such as drawing, interpreting, reducing, and locating positions. This fits well with the RNCS assessment standards which state that learners must be able to provide informal arguments such as drawings, interpretations, and the reducing and locating of positions.

The first three Van Hiele levels (levels zero to two) cover all the assessment standards of the intermediate phase as stated in the RNCS (Department of Education, 2002). Therefore the exit level outcomes for learners in the intermediate phase of the South African curriculum can be related to the expectations of Van Hiele level two.

\section{Methodology}

This study aimed at eliciting learners' understanding within the notion of respecting and recognising the uniqueness of each individual. Open and flexible semi-structured interviews were used in order to allow the interviewer to understand how individuals experience their life- world (Welman \& Kruger, 1999). Bless and Smith (1995) support this technique by stating that it helps to clarify concepts and problems and it allows for discovery of new aspects of the problem by investigating in detail some explanations given by the respondent.

\section{Teachers and schools}

All of the six schools that participated in this study had relatively common backgrounds in terms of the type of mathematics teachers on their staffs. Similarities between the teachers were drawn in terms of the type of mathematics education programmes they had attended, the level of their qualifications in mathematics education and the institution that had provided the educational programmes.

The schools participating in this study were divided into three socio-geographic groups: urban schools, peri-urban schools, and rural schools. Each socio-geographic group was represented by two schools with each school contributing five learners to the study, i.e., a total of 30 learners. Initial inspection of the interview data revealed the learners could be grouped into three Van Heile categories according to the criteria described earlier. The first category, learners who are strictly on thinking level zero of Van Hiele levels, came mostly from rural schools with two from periurban and one from an urban school. There were ten learners in this group.

The second group of learners were located in a band from thinking level zero but progressing to Van Hiele level one. This group of 15 learners were mostly from urban schools; nine came from urban schools, three from peri-urban schools, and three from rural settings. The third group consisted of five learners, all from the same school in a periurban setting. This third group had attained level one of Van Hiele's hierarchy.

\section{Selected learners}

All learners were interviewed, but three learners (each as the most representative individual from each of the three categories described above) were selected for in-depth analysis and description. Each selected participant's background is given below.

Learner A is a girl from a village school in the ex-Transkei area. Four teachers from this school have completed a degree or a diploma in mathematics and science education with the Department of Science, Mathematics and Technology Education (SMATE) at the University of Port Elizabeth (UPE). One of the teachers was 


\section{Nosisi Feza and Paul Webb}

also involved in a diploma (FDE) offered by SMATE as part of the Open Society Science and Mathematics Initiative (OSSMI) that was initiated to train key teachers especially for rural schools. This teacher upgraded his FDE to a Bachelor of Education degree in mathematics and science through UPE and is now a principal of this school. The school is under-resourced, having twelve classrooms and a very small office with muddy floors for the principal. There is no electricity or water in the school.

Learner B is a girl who attended a citytownship school. Two teachers from this school had attended non-formal mathematics education programmes offered by UPE for in-service teachers. One of these teachers was awarded a British Council bursary to study at Leeds University in England. This teacher has subsequently been involved in running workshops for other mathematics teachers in his own and surrounding schools and has been promoted to deputy principal. Compared to the other schools participating in this study the school was relatively well resourced as it had a computer room with computers, a photocopier, water, and electricity.

Learner $\mathrm{C}$ is a boy who attended a township school in a small town situated between the exCiskei and Transkei. Six teachers in this school had obtained their mathematics and science degree or diploma from UPE through SMATE. The learner's mathematics teacher has upgraded her qualifications to the BEd level and had been running a number of workshops for teachers in her area and had recently been promoted to head of department for mathematics in her school. The school was well maintained but lacked resources such as computers and a photocopier.

\section{Manipulatives}

Osborne and Gilbert (1979) suggest a shared external focus of pictures and 'hands on' manipulatives provide a comfortable focus for conversation ranging widely over the rich prior experiences of the learner. Manipulatives were used during the interviews conducted in this study in an attempt to reveal a range and variety of learner understandings. The manipulatives used in this study consist of a picture of a convent school in Lady Frere in the Eastern Cape which allowed the recognition of shapes in complex situations, picture cards of 2-dimensional shapes from threesided shapes to eight-sided shapes. The shapes were made out of thin coloured cardboard. Construction sticks were also used to allow learners to construct shapes and also to probe learners' understandings of concepts of shapes through constructions during the interview. These techniques allowed follow-up questions to be asked which explored the reasons for initial responses (Carr, 1996). In this way the use of the manipulatives helped the researcher match learners' thinking with Van Hiele levels and the RNCS assessment standards.

\section{Interview protocol and approaches}

As this study explores the learner's interpretation of geometrical concepts, the general framework of activities using manipulatives and questions were prepared prior to the interview. The interview began with a request for the learner to respond with his or her own understanding of a focus concept by discussing the manipulatives as they were successively revealed, a method championed by Carr (1996).

As it is impossible to remember all of the complex ideas explored during a lively interview, and attempting a written record takes attention away from careful listening and responding (Carr, 1996), these interviews were recorded on an audiotape recorder and a video recorder. The audio-tape recorder was used to record verbal communication between the interviewer and the interviewee. Then the video recorder was used to take pictures of constructions of geometrical shapes constructed by the interviewee as a response to some questions asked by the interviewer. Fuys et al. (1988) point out the value of video recording these activities as many characteristics are not expressed verbally and may be missed during the interview process.

\section{Data collection}

Data collection and initial data analysis occurred simultaneously as the researcher interacted with the participants. Data analysis included triangulation of on-site observations of learners' geometrical constructions using the manipulatives provided, the interviews held with the learners during this process and the video and audio-tape recordings of the sessions. Although data collection and initial analysis happened at the same time, synthesis across data sources only occurred when data collection for the entire study was completed.

Both Xhosa and English was used during the interviews because second language translation and code switching (using two different language within the conversation) on the part of both teacher and learners occurred regularly (Bantwini, England, Feza, Foster, Lynch, Mgobozi, Peires, \& Webb, 2003). Only learner C used English 
exclusively throughout the interview. The other two learners employed code-switching, with both the interviewer and the participants slipping between Xhosa and English during interview.

One of the major difficulties of research in which the language of the people under study is different from that of the report is gaining conceptual equivalence or compatibility of meaning between the researcher and the participant (Deutscher, 1968; Whyte \& Braun, 1968; Sechrest, Fay \& Zaidi, 1972; Temple, 1997). Vulliamy (1990) asserts that one of the factors to be considered during translation is the researcher's knowledge of the language and the culture of the people under the study, in this case the learners. In this study translation of the data was done by the researcher who is fluent in Xhosa and who shares the same culture and language of the participants. As participants become tired if they are involved for a lengthy period, the interviews were confined to thirty minutes for each learner.

\section{Results}

It was evident from the initial 30 interviews that the learners were clearly not at the same levels of verbal expression, mathematical terminology, or understanding of geometry. The selection of the learner episodes that are used to exemplify the participating learners' levels of understanding was done by first grouping the 30 learners into three appropriate Van Hiele thinking levels as described under 'methodology' above. Ten learners were strictly at level zero, 15 between zero and one, while five learners had fully attained level one (Table 1). learners' responses are presented as three episodes.

The episodes that follow provide examples of verbal expression (their words), mathematical terminology, and apparent level of understanding for each learner. In the presented episodes $\mathrm{R}$ stands for researcher and $\mathrm{L} \mathrm{A}, \mathrm{L} \mathrm{B}$, and $\mathrm{L} \mathrm{C}$ stand for Learners A, B and C respectively.

\section{Episodes with Learner A}

Learner A did not recognise any shapes in the picture of the convent school. As such the following questions were asked:

$\mathrm{R}$ : Do you know the meaning of the word shape?

L A:Yes I do.

R: What do you call this? [Showed the learner a rectangular piece of cardboard]

L A:Right angle

$\mathrm{R}$ : Can you show me other shapes in the picture besides the one you have mentioned?

L A:Pointed to a square but did not name it.

When Learner A was shown picture cards of squares, rectangles, and triangles and asked to name them, she kept quiet. When shown each card one at a time, again she kept quiet and just shrugged her shoulders and gave no verbal response.

During construction activities Learner A was able to construct a rectangle using the construction sticks provided. The following questions were asked, and these answers given, during the construction process:

\begin{tabular}{|l|c|c|c|}
\hline \multirow{2}{*}{ School Type } & \multicolumn{3}{|c|}{ Van Hiele level } \\
\cline { 2 - 4 } & Level zero & Level zero $\rightarrow 1$ & Level 1 \\
\hline Rural School & 7 & 3 & - \\
\hline Peri-urban School & 2 & 3 & 5 \\
\hline Urban School & 1 & 9 & - \\
\hline
\end{tabular}

Table 1. Distribution of number of learners at different Van Hiele levels per school type $(n=30)$

A 'representative' learner for each group was chosen according to the richness and clarity of the responses that they gave during their initial interviews and also in terms of their apparent suitability for representing the other learners in the category i.e., they gave answers that were clear examples of the criteria used to categorise the responses in terms of Van Hiele levels. These
$\mathrm{R}$ : What must happen to the angles of your rectangle as you construct it?

L A: I do not know angles but I know that there should be four corners.

$\mathrm{R}$ : What must happen to the sides of your rectangle?

L A: Two sides should be equal and other two should also be equal. 


\section{Nosisi Feza and Paul Webb}

When asked to construct a square, Learner A again constructed a rectangle. Then the following questions were asked:

R: Tell me every step you do while constructing the square.

L A:I take two equal sticks and other two equal sticks. Then the two equal sides should look at one another.

When asked to construct any triangle, Learner A constructed an equilateral triangle and explained that it should have three sides. When given a selection sheet of different shapes and asked to identify rectangles, she pointed to all the rectangles and stated that she recognises a rectangle by four corners. When asked to identify parallel lines, Learner A showed understanding that lines are parallel if the distance between them is equal. This was evident by the fact that she gave an example of power lines but did not use the mathematical word for the concept. When asked to identify parallel lines in a selection sheet, she did not respond.

Learner A was presented with a number of shapes that had been sorted by number of sides and angles into quadrilaterals, triangles, pentagons, hexagons, and octagons. She was asked to guess the rule by which the shapes had been sorted. In response she suggested that the shapes are sorted according to similar colour. She went further by saying that "the shapes look alike". When the researcher again asked the learner to describe the sorting procedure and to give names to the shapes in each group, her response was "only triangles other shapes are not the same".

The researcher then showed the learner a group of quadrilaterals and asked the following:

R: How could we place these shapes into groups that belong together?

L A:[Silent, she was sorting the shapes.]

R: How are you sorting the shapes?

L A:[Silent, she sorted squares together, rectangles together, parallelograms and rhombi together, and trapeziums together.]

$\mathrm{R}$ : [Pointing a group of squares.] If you were talking with your friend over the phone and you wanted to describe these pieces, what could you say about them?

L A: The sides are equal like a box.

Questions on quadrilaterals followed:

R: When you sorted the first set of shapes, do you remember that you had a group of triangles, and one of the quadrilaterals or four-sided figures, and five-sided ones, and six- sided ones. Where would all the shapes on the table belong?

L A: Four-sided shapes.

Although she referred to the quadrilaterals as foursided shapes, a response reflecting Van Hiele level one, it was the only time she did this, and it is possible that she copied the researcher's words when she posed the question. The following inclusion activity questions were asked and the following responses were received.

R: [The researcher picks up a square from a selection of figures sorted into squares, rectangles, parallelograms, trapeziums, triangles and polygons.] So I could move this square to the quadrilateral or foursided shapes - a square is a special kind of a quadrilateral. What makes it special?

L A: [Says nothing.]

$\mathrm{R}$ : Can we move the square to the rectangle group?

L A: Yes.

R: Why?

LA: Because it has four corners.

R: Someone yesterday said that a square is a special kind of a rectangle with equal sides. Do you think she could be right?

L A: Yes, because it has four corners.

R: What do you think she said when she put a square in a parallelogram pile?

L A: [Silent.]

$\mathrm{R}$ : Would she have put a rectangle in the parallelogram pile? What would she have said?

L A: No.

R: Would it be possible to call every square a rectangle?

LA: Yes, because you can put squares together they make a rectangle.

R: Would it be possible to call every rectangle a square?

L A: No, because a rectangle has two equal sides but the square has four equal sides.

This learner has not attained sufficient mathematical vocabulary in order to express herself coherently. Her conceptual understanding also appears to be under-developed because she used sorting according to colour, and sorting according to a "look like" basis. There was no use of properties at all in her statements, her definition of shapes confirmed this as she defined a square as 
something with four sides like a box, and did not seem to be aware that a box is a 3-dimensional object not a 2-dimensional shape. The learner could only recognise a square, could not name shapes, could not describe or classify shapes using properties, could not construct shapes correctly and, as such, was considered not to have progressed beyond level zero in terms of shapes of objects or have achieved the assessment standards or have attained learning outcome three from the RNCS which states that:

The learner will be able to describe and represent characteristics and relationships between two-dimensional shapes and three-dimensional objects in a variety of orientations and positions. (RNCS, 2002: 48)

In terms of language as an obstacle in learning geometry Learner A's responses show that her development is blocked by language. When she has to name shapes she becomes quiet but when she is asked to construct these shapes she does not struggle. Therefore the fact that she cannot name them does not mean that she does not know them because she constructs the shapes using correct properties.

\section{Episodes with Learner B}

Learner B recognised the shapes from the picture and selection sheets and named them correctly with the exception of parallelograms. In this case she simply looked at them and shook her head. She constructed a rectangle, defined it as a shape with four corners and went further by mentioning that two opposite sides are equal (not two pairs of opposite sides). She constructed a square and defined it as a shape with four equal sides and constructed a triangle, defining it as a shape with three sides.

Learner B showed understanding of the concept of parallel lines and also gave an example of electric power lines. When identifying parallel lines in a selection sheet she identified them as "equal lines". During sorting activities the following conversation took place between the researcher and the learner:

$\mathrm{R}$ : [The researcher showed the learner a collection of cardboard cut-out polygons.] These shapes came from several different boxes but they got all mixed up. This is how someone tried to put them back in groups, which belong together. [She then sorted just the first four shapes according to equal number of sides. Picking up a square she said,] "Can you guess where this one belongs?"

L B: [Silent.]

R: Can you describe how the pieces were sorted and what their names are?

L B: Triangles are together.

$\mathrm{R}$ : [The researcher showed the learner a group of quadrilaterals.] How could we place these into groups of things that belong together?

L B: We can group them into squares, rectangles, and rhombuses.

$\mathrm{R}$ : How are you sorting these shapes?

L B: According to shapes.

R: [She pointed squares.] If you were talking with your friend over the phone and you wanted to describe these pieces, what could you say about them?

L B: A square looks like a box, and has four corners.

The learner also described a rectangle as a longer square but could not describe a parallelogram. She recognised squares and said "they look like a box and have four corners". The researcher showed the learner a group of quadrilaterals and continued the conversation as follows:

$\mathrm{R}$ : When you sorted the first set of shapes, do you remember that you had a group of triangles, and one of the quadrilaterals or four-sided figures, and five-sided ones, and sixsided ones. Where would all the shapes on the table belong?

L B: Four-sided group.

R: [She picked up a square.] So I could move this square to the quadrilateral or four-sided group. A square is a special kind of a quadrilateral. What makes it special?

L B: [Silent.]

$\mathrm{R}$ : Can we move the square to the rectangle group?

L B: Yes.

R: Why?

L B: They all have four corners.

$\mathrm{R}$ : Someone yesterday said that a square is a special kind of a rectangle with equal sides. Do you think she could be right?

L B: [Silent.] 


\section{Nosisi Feza and Paul Webb}

The researcher probed for a response but Learner B kept quiet until the researcher suggested that someone put the rectangle in the parallelogram pile and asked what the learner thought the reason for that was. The learner's response was that parallelograms look like rectangles and have four corners. Then the researcher continued.

$\mathrm{R}$ : Would it be possible to call every square a rectangle? Could I move a rectangle to the square group?

L B: Yes, because it has four corners.

R: Would it be possible to call every rectangle a square?

L B: Yes, because it has four corners.

When asked to guess the rule used by the researcher when sorting using parallel lines, the learner described parallelograms as straight shapes and trapeziums as shapes made from triangles. To her, angles were corners. It is possible that language may have constituted a further barrier to learning.

At school, a rectangle is called "uxande" in Xhosa, whereas at home "uxande" is used to describe a rectangular house. Because the word "angle" is not used in vernacular Xhosa, this may have created difficulties in seeing a difference between a square and a rectangle as each has four corners.

Learner B's thinking differs from Learner A's in that she used the correct names for shapes and recognised all except for the parallelogram. Her concept of shapes is moving towards level one of Van Hiele's levels. However, the language that she used suggested that there was still a need for further development to meet all the requirements of level one. Her definitions and descriptions suggested that she had an adequate understanding of shapes and their properties, but that she lacked the vocabulary to express her understanding, therefore she struggled to define the sorting of shapes and was not able to find words to describe what she saw and did.

Learner B defined shapes on a 'look-like something' basis. When she defined a trapezium she described it as "a shape made from a triangle". To her the word 'parallel' is synonymous to 'straight'. Thus it appeared she lacks vocabulary rather than understanding and this was possibly the factor that prevented her from being categorised at Van Hiele level one. Van Hiele (1986) notes that each level of thinking has its own language standard that needs to be attained.

The RNCS assessment standards require learners to describe and classify shapes using properties and this learner lacked the vocabulary to do this. The RNCS assessment standards also require learners to describe the relationship between shapes using properties of rotations, reflections, and translations. This learner identified the number of corners as the common element for all quadrilaterals, but made no reference to rotation, reflection or translation in her argument.

\section{Episodes with Learner C}

Learner $\mathrm{C}$ recognised all the shapes (octagon, hexagon, and rhombus) in the picture of the convent school and was able to name them correctly. He also recognised triangles, squares, rectangles, and parallelograms from picture cards and named them correctly.

During construction activities, this learner constructed a rectangle correctly. The researcher asked follow-up questions as follows:

$\mathrm{R}$ : What must happen to the angles of your rectangles as you construct it?

L C: All four angles must be 90 degrees.

$\mathrm{R}$ : What must happen to the sides of your rectangle?

LC: Two opposite sides should be equal.

When asked to construct a square, Learner C took four stick lengths and mentioned that all four sides of a square should be equal. Then he was asked to construct a triangle. He constructed a triangle stating that it must have three sides. When asked to observe a selection sheet of shapes, Learner $\mathrm{C}$ pointed to rectangles and stated that they are rectangles because they have two opposite sides that are equal.

During parallel line activities this learner showed an understanding of the concept and gave a relevant example of electric power lines. When asked to guess the researcher's rule in sorting activities, Learner $\mathrm{C}$ suggested that sorting had been done according to sides. When describing sorting he mentioned that shapes are grouped into "quadrilaterals, triangles, hexagons, and hotagons" (in the place of octagons).

The researcher then showed the learner a group of quadrilaterals and asked:

R: How could we place these [showing the learner different quadrilaterals) into groups of things that belong together?

L C: Rectangles together, squares together and rhombuses together.

R: How are you sorting the shapes?

L C: According to shapes.

When Learner $\mathrm{C}$ was asked to describe a square to a friend who could not see the shape, he said "a square is a shape with four equal sides" and 
described a rectangle as "a shape with two pairs of parallel sides and two pairs of equal sides". A parallelogram was described as "a shape with two angles that are less than 90 degrees and two angles that are greater than 90 degrees". He also noted "a parallelogram also has four sides".

The researcher continued with quadrilateral activities in the following manner:

R: [The researcher showed the learner a group of quadrilaterals.] When you sorted the first set of shapes, do you remember that you had a group of triangles, and one of the quadrilaterals or four-sided figures, one of five-sided figures, and one of six-sided figures. Where would the shapes on the table belong?

L C: Four sided group.

R: [She picked up a square.] So I could remove this square to the quadrilateral or four-sided group would you accept it if I say a square is a special kind of a quadrilateral. If you do, what makes it special?

L C: [Silent.]

$\mathrm{R}$ : Can we move the square to the rectangle group?

L C: Yes.

R: Why?

L C: Because a square has four sides.

$\mathrm{R}$ : Someone said yesterday that a square is a special kind of a rectangle with equal sides. Do you think she could be right?

L C: [Silent.]

R: What do you think she said when she put a square in a parallelogram pile?

L C: [Silent.]

R: Might she have put a rectangle in the parallelogram pile? What would she have said?

L C: A parallelogram is a slanting rectangle.

$\mathrm{R}$ : Would it be possible to call every square a rectangle? Could I move

L C: No. this rectangle to the square group?

R: Why?

L C: The square has four equal sides.

$\mathrm{R}$ : Would it be possible to call every rectangle a square?

L C: No.

R: Why?
L C: Because the rectangle has two long sides and two short sides.

The researcher sorted a number of quadrilaterals according to parallelism (without including any squares or rectangles) and asked the following questions:

$\mathrm{R}$ : Look at my sorting. Can you guess my rule? How did I sort the shapes?

$\mathrm{L} \mathrm{C}$ : The rule is shapes with two pairs of parallel lines together and shapes with one pair of parallel lines together. Therefore the shapes are grouped in parallelograms and trapeziums.

During the entire interview this learner responded fluently in English. He recognised shapes and used correct mathematical terminology when naming the shapes. When naming the shapes he used his hands to indicate the shape he was mentioning by pointing at the picture and drawing the shape in the air. He used the correct terms for each shape, except the octagon which he named "a hotagon" which may be either a tongue fluency problem or a sound based problem (Bantwini et. al., 2003).

Learner $\mathrm{C}$ defined shapes using angles, sides, and parallelism, showing that he had a good grasp of these geometric concepts. His constructions of shapes showed that he had an understanding of accuracy as he measured by comparing the sticks before constructing the shapes. However, this learner did not appear to notice any relations between shapes when sorting them, as he sorted the shapes using their individual properties without commenting on any common properties. This suggests that his level of thinking was at Van Hiele level one, i.e., that he had attained both levels zero and one, but has not progressed from level one towards level two. He still defined shapes in an isolated way and did not use the properties of rotations and the vocabulary as required by the RNCS assessment standards.

\section{Discussion}

The episodes described above with the grade seven learners, who had been identified as being representative of the three categories, suggest that none of the 30 learners had attained the requirements of the RNCS assessment standards or could be categorised at Van Hiele level two.

Burger and Shaughnessy (1986), as well as Dickson, Brown and Gibson (1984) assert that many learners in the middle years of schooling have severe misconceptions concerning a number of important geometric ideas. De Villiers and 


\section{Nosisi Feza and Paul Webb}

Njisane (1987), and Govender (1995), in their studies in South African schools indicate that grade 12 learners and high school learners in general are still functioning more at concrete and visual levels than at an abstract level in geometry, in spite of the fact that the national school exit examination requires a clear understanding of underlying abstract processes. De Villiers (1987) notes that this, and the fact that the transition from concrete to abstract levels of thinking, poses "specific problems to second language speakers". De Villiers (1987) also notes that, "since success in geometry also involves the acquisition of the technical terminology", there is little wonder that our learners perform so poorly.

Findings in this study also suggest that language competency in general is a barrier to the attainment of higher levels of understanding amongst this group of learners, over and above Van Hiele's notion that each level of geometrical thinking has its own language (Fuys \& Liebov, 1997). This raises the issue of how to overcome language as a barrier for learners who speak English as a second language, a universal feature in multilingual societies.

What is important in terms of pedagogy is that people at different levels of mathematical understanding speak, use and understand terms differently, and that teachers often use terms that can only be understood by learners who have progressed to the third or fourth Van Hiele level (Wirszup, 1976). Consequently, when trying to communicate with learners who operate at lower levels, teachers' intentions may be completely misunderstood. As such it is crucial that geometry teachers investigate their learners' understanding in order to be able to provide meaningful learning experiences at their particular level of development.

One way of enabling teachers to use Van Hiele levels and the RNCS Assessment Standards to establish their learners' levels of geometrical understanding is to provide experience of Van Hiele levels in pre- and in-service training opportunities, by engaging them in activities that require classifying of answers by Van Hiele level, and by challenging them to match these responses to the RNCS Assessment Standards.

Not only Van Hiele levels and assessment standards, but also learners' cultural background and their specific use of words in the vernacular context, need to be taken into consideration by teachers when developing learning programmes. A possible strategy to attain all the requirements noted above is an inquiry approach where teachers and learners engage in conversations that allow teachers to ascertain prior knowledge, language use, cultural frameworks and levels of understanding of learners in terms of a particular topic, and which in turn allow learners to discern the direction further study will take (Lindquist, 1987).

Finally, the fact that the three different learners interviewed were from three different schools, yet all mentioned telegraph lines as examples of parallel lines suggests that their teachers possibly rely on limited knowledge from textbooks or training courses that they have not adapted or elaborated for themselves. This raises the question of whether we are exploring learners' understandings of geometry during interviews or merely hearing what the learners think school mathematics is all about or what their teachers would expect them to say. The relationship is complex, but it seems reasonable to propose that teachers relying on limited knowledge would benefit from exploring shapes themselves in their everyday language before they can be expected to consider the implications of Van Heile levels and the RNCS Assessment Standards.

\section{References}

Austin, J.L. \& Howson, A.G. (1979). Language and mathematical education. Educational Studies in Mathematics, 10, 161-197.

Bantwini, B., England, V., Feza, N., Forster, L., Lynch, P., Mgobozi, N., Peires, M., \& Webb, P. (2003). The dynamics of learning in multilingual science classrooms: Investigating the languages used by primary school teachers and learners in whole class discussion in science lessons and their role in promoting understanding. Proceedings of the $10^{\text {th }}$ Annual meeting of the South African Association for Research in Mathematics, Science and Technology Education (SAARMSTE) (pp. 418422). Natal, South Africa: SAARMSTE.

Bishop, J. A. (1997). Space and Geometry. In R. Lesh \& M. Landau. (Eds.), Acquisition of Mathematics Concepts and Processes (pp. 175226). Evanston, Illinois: Academic Press.

Bless, C. \& Smith, C.J. (1995). Fundamentals of Social Research Methods: An African Perspective. Second Edition. Cape Town: Juta $\&$ Co, Ltd.

Burger, W.F. \& Shaughnessy, J.M. (1986). Characterizing the van Hiele levels of development in geometry. Journal for Research in Mathematics Education, 17, 31-48. 


\section{Assessment standards, Van Hiele levels, and grade seven learners' understandings of geometry}

Carpenter, T.P. \& Fennema, E. (1988). Research and cognitively guided instruction. In $\mathrm{E}$. Fennema, T.P. Carpenter \& S.J. Lamon (Eds.), Integrating research on teaching and learning mathematics (pp 2-17). Madison: Wisconsin Center for Education Research, University of Wisconsin.

Carr, M. (1996). Interviews About Instances and Interviews About Events. In D.F. Treagust, R. Duit \& B.J. Fraser (Eds.), Improving Teaching and Learning in Science and Mathematics education (pp. 44-53). New York: Teachers College Press.

Davies, J. (1986). Crisis, Education and Restructuring in South Africa. In R. Sharp (Ed.), Capitalist Crisis and Schooling.: Comparative studies in the politics of education (pp. 237-264). Melbourne, Australia: MacMillan.

De Lange, J. (1981). Teaching of Natural Science and Mathematics. Pretoria: Human Sciences Research Council.

De Villiers, M. D. (1987). Research evidence on hierarchical thinking, teaching strategies and the Van Hiele theory: Some critical comments. Internal RUMEUS report number 10, University of Stellenbosch, South Africa.

De Villiers, M. D. \& Njisane, R. M. (1987). The Development of geometric thinking among Black High School pupils in KwaZulu (Republic of South Africa), Proceedings of $11^{\text {th }}$ Conference of the International Psychology of Mathematics Education, 3 (pp. 117-123). Montreal, Canada.

Department of Education (2002). Revised National Curriculum Statement. Assessment standards for mathematics education. Pretoria: National Education Department.

Deutsher, I. (1968). Asking questions CrossCulturally: Some Problems of Linguistic Comparability. In H. S. Becker, B. Geer, D. Riesman \& R. S. Weiss (Eds.), Institutions and the Person (pp. 318-341). Chicago: Aldine Publishing Company.

Dickson, L., Brown, M. \& Gibson, O. (1984). Children learning mathematics: A teacher's guide to research. East Sussex, UK: Holt, Rinehart and Winston.

Fuys, D. \& Liebov, A.K. (1997). Concept Learning in Geometry. Teaching Children Mathematics, 3 (5), 248-251.

Govender, M. (1995). Pupils' proof-writing achievement in circle geometry. Unpublished
BEd.dissertation, University of DurbanWestville.

Hartshorne, K. (1992). Crisis and Challenge: Black Education 1910-1990. Cape Town: Oxford University Press.

Kempa, R. F. (1993). Science education research and the practice of science education. Keynote address presented at the International Conference on Science Education in Developing Countries: From Theory to Practice, Jerusalem, Israel.

Lindquist, M. M. (1987). Learning and Teaching Geometry, K-12. National Council of Teachers of Mathematics (NCTM), Albert P. Shulte (Eds).Oakland Schools. Michigan: Pontiac

Mansfield, H. \& Happs, J. (1996). Improving Teaching and Learning in Science and Mathematics. Using Student Conceptions of Parallel lines to Plan a Teaching Program. New York: Columbia University.

McAuliffe, S. M. (1999). An Analysis of the impact of a geometry course on pre-service teachers understanding of geometry. Unpublished MEd dissertation, University of Cape Town.

Osborne, R. J., \& Gilbert, J. K. (1979). Investigating student understanding of basic physics concepts using an interview - about instances approach. Research in Science Education, 12, 59-87.

Peterson, P.L. (1998). Teachers' and Students' cognitional knowledge for classroom teaching and learning. Educational Researcher, 17 (5), 5-14.

Raborn, D. R. (1995). Mathematics for Students with Learning Disabilities from LanguageMinority Backgrounds: Recommendations for Teaching. New York State Association for Bilingual Education Journal, 10, 25-33.

Samuel, J. (1990). The State of Education in South Africa. Education from Poverty to Liberty. Cape Town: David Philip.

Sechrest, L., Fay, T. L. \& Zaidi, S. M. H. (1972). Problems of translation in cross-cultural research. Journal of Cross-Cultural Psychology, 3(1), 41-56.

Temple, B. (1997). Watch your tongue: issues in translation and cross-cultural research. Sociology, 31(3), 607-618.

Van Hiele, P. M. (1984). A child's thought and geometry. In D. Fuys, D. Geddes, \& R. Tischler (Eds.), English translation of selected writings of Dina van Hiele-Geldof and P.M.van Hiele. (pp. 242-252). Brooklyn: Brooklyn College. 


\section{Nosisi Feza and Paul Webb}

Van Hiele, P. M. (1986). Structure and insight: A theory of mathematics education. Orlando: Academic Press.

Vulliamy, G. (1990). Research Outcomes: PostScript. In G. Vulliamy, K. Lewin \& D. Stephens (Eds.), Doing Educational Research in Developing Countries: qualitative strategies (pp. 169-233). London: The Falmer Press.

Welman, J.C. \& Kruger, S.J. (1999). Research Methodology for the Business and Administrative Sciences. Third edition. Johannesburg: International Thomson Publishing (Pty) Ltd.
Whyte, W. F. \& Braun, R. R. (1968). On language \& Culture. In H. S. Becker, B. Geer, D. Riesman and R. Weiss (Eds.), Institutions and Person (pp. 119-138). Chicago: Aldine Publishing Company.

Wirszup, I. (1976). Breakthroughs in the psychology of learning and teaching geometry. In J. L. Matin (Ed.), Space and Geometry: Papers from a research workshop (pp. 75-97). Colombus, Ohio: ERIC.

"We teach best what

we most need to

learn."

Richard Bach 